Zock, J.P., Rodríguez-Trigo, G., Rodríguez-Rodríguez, E., Souto-Alonso, A., Espinosa, A., PozoRodríguez, F., Gómez, F.P., Fuster, C., Castaño-Vinyals, G., Antó, J.M., Barberà, J.A. Evaluation of the persistence of functional and biological respiratory health effects in clean-up workexs 67 years after the Prestige oil spill. Environment International: 2014, 62(1), 72-77

\begin{tabular}{|l|l|}
$\begin{array}{l}\text { Postprint } \\
\text { Version }\end{array}$ & 1.0 \\
\hline Journal website & $\underline{\text { http://www.sciencedirect.com/science/article/pii/S0160412013002146 }}$ \\
\hline Pubmed link & $\underline{\text { http://www.ncbi.nlm.nih.gov/pubmed/24184661 }}$ \\
\hline DOI & $10.1016 /$ j.envint.2013.09.020 \\
\hline
\end{tabular}

This is a NIVEL certified Post Print, more info at http://www.nivel.eu

\title{
Evaluation of the persistence of functional and biological respiratory health effects in clean-up workers 6 years after the Prestige oil spill
}

\author{
JAN-PAUL ZOCK ${ }^{\mathrm{A}, \mathrm{B}, \mathrm{C},}$, GEMA RODRÍGUEZ-TRIGO ${ }^{\mathrm{D}, \mathrm{E}}$, EMMA RODRÍGUEZ-RODRÍGUEZ ${ }^{\mathrm{F}}$, ANA \\ SOUTO-ALONSO ${ }^{\mathrm{G}}$, ANA ESPINOSA ${ }^{\mathrm{A}, \mathrm{B}, \mathrm{C}}$, FRANCISCO POZO-RODRÍGUEZ $^{\mathrm{E}, \mathrm{H}}$, FEDERICO P. \\ GÓMEZ $^{\mathrm{E}, \mathrm{I}}$, CARME FUSTER', GEMMA CASTAÑO-VINYALS ${ }^{\mathrm{A}, \mathrm{B}, \mathrm{C}}$, JOSEP MARIA ANTÓ ${ }^{\mathrm{A}, \mathrm{B}, \mathrm{C}, \mathrm{K}}$, \\ JOAN ALBERT BARBERÀ ${ }^{\mathrm{E}, \mathrm{I}}$ \\ ${ }^{a}$ Centre for Research in Environmental Epidemiology (CREAL), Barcelona, Spain \\ ${ }^{\mathrm{b}}$ Hospital del Mar Medical Research Institute (IMIM), Barcelona, Spain \\ c CIBER Epidemiología y Salud Pública (CIBERESP), Spain \\ ${ }^{\mathrm{d}}$ Department of Respiratory Medicine, Hospital Clínico San Carlos, Madrid, Spain \\ ${ }^{\text {e }}$ CIBER Enfermedades Respiratorias (CIBERES), Bunyola, Mallorca, Spain \\ ${ }^{\dagger}$ Complexo Hospitalario Universitario, A Coruña, Spain \\ ${ }^{g}$ Department of Respiratory Medicine, Hospital Arquitecto Marcide, Ferrol, Spain \\ ${ }^{\mathrm{h}}$ Department of Respiratory Medicine and Clinical Epidemiology Unit, University Hospital 12 \\ de Octubre, Madrid, Spain \\ ' Department of Respiratory Medicine, Hospital Clínic-Institut d'Investigacions Biomèdiques \\ August Pi i Sunyer (IDIBAPS), Barcelona, Spain \\ j Unit of Cellular Biology and Medical Genetics, Faculty of Medicine, Autonomous University \\ of Barcelona (UAB), Barcelona, Spain \\ ${ }^{k}$ Department of Experimental and Health Sciences, Universitat Pompeu Fabra (UPF), \\ Barcelona, Spain
}

\begin{abstract}
Fishermen who had participated in clean-up activities of the Prestige oil spill showed increased bronchial responsiveness and higher levels of respiratory biomarkers 2 years later. We aimed to evaluate the persistence of these functional and biological respiratory health effects 6 years after clean-up work. In 2008/2009 a follow-up study was done in 230 never-smoking fishermen who had been exposed to clean-up work in 2002/2003 and 87 non-exposed fishermen. Lung function and bronchial responsiveness testing and the determination of respiratory biomarkers in exhaled breath condensate were done identically as in the baseline survey in 2004/2005. Associations between participation in clean-up work and respiratory health parameters were assessed using linear and logistic regression analyses adjusting for sex and age. Information from 158 exposed (69\%) and 57 non-exposed (66\%) fishermen was obtained. Loss to follow-up in the non-exposed was characterised by less
\end{abstract}


Zock, J.P., Rodríguez-Trigo, G., Rodríguez-Rodríguez, E., Souto-Alonso, A., Espinosa, A., PozoRodríguez, F., Gómez, F.P., Fuster, C., Castaño-Vinyals, G., Antó, J.M., Barberà, J.A. Evaluation of the persistence of functional and biological respiratory health effects in clean-up workers 67 years after the Prestige oil spill. Environment International: 2014, 62(1), 72-77

respiratory symptoms at baseline. During the 4-year follow-up period lung function, bronchial hyperresponsiveness and the levels of respiratory biomarkers of oxidative stress and growth factors had deteriorated notably more among non-exposed than among exposed. At follow-up, respiratory health indices were similar or better in clean-up workers than in non-exposed. No clear differences between highly exposed and moderately exposed clean-up workers were found. In conclusion, we could not detect long-term respiratory health effects in cleanup workers 6 years after the Prestige oil spill. Methodological issues that need to be considered in this type of studies include the choice of a non-exposed control group and limitation of follow-up to subgroups such as never smokers.

\section{Abbreviations}

- $\mathrm{FEV}_{1}$, Forced Expiratory Volume in the first second;

- FVC, Forced Vital Capacity;

- $\mathrm{FEF}_{25-75 \%}$, Mean Forced Expiratory Flow between 25\% and 75\% of the FVC;

- BHR, Bronchial Hyperresponsiveness;

- EBC, Exhaled breath condensate;

- IL, Interleukin;

- TNF, Tumour Necrosis Factor;

- VEGF, Vascular Endothelial Growth Factor;

- bFGF, Basic Fibroblast Growth Factor;

- SF, San Francisco quality of life questionnaire;

- GM, Geometric Mean;

- SD, Standard Deviation;

- OR, Odds Ratio

\section{INTRODUCTION}

Large marine oil spills are environmental disasters that typically mobilise large numbers of clean-up workers. There is growing concern about the chemical exposures that clean-up activities involve, and their potential health effects (Goldstein et al., 2011). The wreckage of the oil tanker Prestige in November 2002 heavily contaminated the coast of Galicia, Spain. Hundreds of thousands of emergency responders participated in clean-up operations, including many local fishermen who were among the highest exposed populations. A questionnaire survey among 6780 fishermen in 2004 showed an increased prevalence of respiratory symptoms among fishermen more than one year after having participated in clean-up work ( Zock et al., 2007). The risk was higher when clean-up work was done for a longer period and for a limited use of respiratory protective devices. A more detailed respiratory health assessment performed shortly after the questionnaire survey (2004-2005) included 501 fishermen who had been highly exposed to clean-up work and 177 non-exposed individuals ( Rodríguez-Trigo et al., 2010). Particularly among lifetime non-smokers, there was evidence of increased non-specific bronchial responsiveness and increased levels of 8-isoprostane and growth factors in exhaled 
Zock, J.P., Rodríguez-Trigo, G., Rodríguez-Rodríguez, E., Souto-Alonso, A., Espinosa, A., PozoRodríguez, F., Gómez, F.P., Fuster, C., Castaño-Vinyals, G., Antó, J.M., Barberà, J.A. Evaluation of the persistence of functional and biological respiratory health effects in clean-up workexs 6 years after the Prestige oil spill. Environment International: 2014, 62(1), 72-77

breath condensate in the exposed. The latter suggested a potential involvement of oxidative stress as a mechanism of airway damage and a lasting airway remodelling process.

Very few longitudinal studies have assessed long-term health effects of oil spills. A follow-up study with telephone interviews performed in 2008 showed that more than five years after the Prestige oil spill, clean-up workers more often reported respiratory symptoms than non-exposed, and that the persistence of symptoms was related to the degree of exposure ( Zock et al., 2012). Here we aim to evaluate whether objectively measured functional and biological respiratory health effects had persisted four years after the initial assessment in 2004/2005 ( Rodríguez-Trigo et al., 2010). We hypothesise that exposure to clean-up work of the spilled oil and/or degradation products would be associated with long-term respiratory health effects reflected by a lower lung function, increased bronchial responsiveness and increased levels of biomarkers of oxidative stress and growth factor activity.

\section{METHODS}

\subsection{Study design and participants}

A follow-up study in fishermen was conducted between November 2008 and April 2009, that is, on average four years after the initial clinical evaluation (RodríguezTrigo et al., 2010) and six years after the Prestige oil spill and the related exposure to clean-up work ( Fig. 1). Similar as in the baseline study, in the clinical survey groups of exposed and non-exposed were alternated. Eligible study participants were 230 exposed and 87 non-exposed fishermen who had been included in the initial clinical evaluation and reported never having smoked ( Rodríguez-Trigo et al., 2010). The project was approved by the Ethics Committee on Clinical Research of Galicia, and all participants provided written informed consent.

\subsection{Assessment of respiratory health indices}

Respiratory function testing and the determination of biological markers were done following the same methodology and equipment as detailed in the previous evaluation (Rodríguez-Trigo et al., 2010) by the same trained research nurses. Briefly, participants underwent forced spirometry testing yielding the forced expiratory volume in the first second $\left(\mathrm{FEV}_{1}\right)$, the forced vital capacity (FVC) and the mean forced expiratory flow between $25 \%$ and $75 \%$ of the FVC $\left(\mathrm{FEF}_{25-75 \%}\right)$ according to international guidelines and quality criteria (Miller et al., 2005). Methacholine challenge testing was performed using dosimetry and non-specific bronchial hyperresponsiveness (BHR) was defined as a 20\% decrease in FEV 1 associated with a methacholine dose of $2 \mathrm{mg}$ or less.

Exhaled breath condensate (EBC) samples were obtained by using an EcoScreen condenser (Jaeger, Wirzburg, Germany) following international recommendations (Horvath et al., 2005). In EBC samples we measured the oxidative stress marker 8isoprostane using an enzyme immunoassay. In addition, we measured 10 cytokines and growth factors (interleukin [IL]-1 $\beta, 2,4,6$, and 8; tumour necrosis factor- $\alpha$ 
Zock, J.P., Rodríguez-Trigo, G., Rodríguez-Rodríguez, E., Souto-Alonso, A., Espinosa, A., PozoRodríguez, F., Gómez, F.P., Fuster, C., Castaño-Vinyals, G., Antó, J.M., Barberà, J.A. Evaluation of the persistence of functional and biological respiratory health effects in clean-up workexs 67 years after the Prestige oil spill. Environment International: 2014, 62(1), 72-77

(TNF- $\alpha$ ); interferon- $ү$; vascular endothelial growth factor [VEGF]; monocyte chemotactic protein-1; and basic fibroblast growth factor [bFGF]) that are representative of Th1/Th2 inflammation and airway remodelling using the Cytometric Bead Arrays Flex System (BD Biosciences, Erembodegem, Belgium). Quality of life had been assessed at baseline only using the short Spanish version of the San Francisco quality of life questionnaire (SF-12v1 ${ }^{\mathrm{TM}}$ Health Survey®) allowing the distinction of physical and mental components (Vilagut et al., 2008).

\subsection{Data analysis}

We compared demographic and baseline respiratory health characteristics between participants and non-participants, separately for the exposed and the non-exposed groups. The distribution of 8-isoprostane concentrations in EBC was skewed to the right and values were log-transformed before parametric analyses. Levels of each of the 10 other biomarkers measured in EBC were dichotomised by using the lower limit of detection provided by the manufacturer as the cut-off point. Associations between exposure to clean-up work and respiratory health outcomes were evaluated by using multivariable linear (lung function and log 8-isoprostane) or logistic (BHR and cytokines in EBC) regression analyses adjusting for sex and age and additionally for height in analyses concerning lung function variables. The linear regression coefficients for log 8-isoprostane on exposure were back-transformed in order to obtain an adjusted geometric mean (GM) ratio between exposed and non-exposed. Statistical analyses were done with Stata version 10 (StataCorp, College Station, TX, USA).

\section{RESULTS}

\subsection{Participation and loss to follow-up}

Clinical testing was done in 158 exposed (participation rate 69\%) and 57 nonexposed individuals (66\%). The most important reasons for loss to follow-up were refusal of further participation (34\%) and not showing up at the clinical visit in spite of previous agreement (36\%) (Supplementary Table 1). There were several significant differences in demographic and baseline respiratory health characteristics between participants and non-participants (Supplementary Table 2). Among the nonexposed but not among the exposed, participants were more likely than nonparticipants to have reported any lower respiratory tract symptom at baseline. Thus, at follow-up symptomatic non-exposed appear to be over-represented as compared to the baseline study. Further, exposed individuals who had reported at baseline anxiety or the belief that the oil spill had affected their health were more likely to participate in the follow-up survey. No significant differences in perceived quality of life between those who did and did not take part in the follow-up study were found. We evaluated to what extent the observed differential participation of the nonexposed according to their respiratory symptoms at baseline could have introduced a selection bias. We re-assessed the associations between exposure to clean-up work and selected respiratory health outcomes at baseline for the subsample of participants of the follow-up study (Supplementary Table 3). Overall the differences in BHR and levels of biomarkers in EBC between the exposed and the non-exposed remained similar, although there was a tendency that the spirometric flow variables were lower 
Zock, J.P., Rodríguez-Trigo, G., Rodríguez-Rodríguez, E., Souto-Alonso, A., Espinosa, A., PozoRodríguez, F., Gómez, F.P., Fuster, C., Castaño-Vinyals, G., Antó, J.M., Barberà, J.A. Evaluation of the persistence of functional and biological respiratory health effects in clean-up workers 6 years after the Prestige oil spill. Environment International: 2014, 62(1), 72-77

among the non-exposed when analysing participants of the follow-up. Thus, a better lung function was suggested among exposed as compared to non-exposed when using this selected study population.

\subsection{Changes in respiratory health outcomes during the follow-up period}

The following analyses were done for individuals who participated in both the baseline and follow-up surveys (Table 1). The follow-up time was similar in both groups. Exposed were studied between 3 December 2008 and 14 April 2009 (median 11 February 2009) while non-exposed were studied between 20 November 2008 and 8 April 2009 (median 27 January 2009). Consistent with the initial survey, exposed participants were on average younger and more likely to be male. Body mass index was relatively high in both groups, and did not change much during follow-up. At the end of follow-up, about $20 \%$ of both exposed and non-exposed participants were no longer employed as fisherman or shellfish gatherer; the vast majority had retired or were not working for other reasons. Both at baseline and at follow-up the prevalence of asthma was slightly higher among the non-exposed.

There were marked changes in health outcomes between baseline and follow-up, in particular for the non-exposed (Fig. 2). In this group the prevalence of BHR and the levels of 8-isoprostane and both growth factors in EBC had increased strongly during the four-year follow-up period, while the changes for the exposed were on average smaller and for VEGF levels even decreased. As expected, the $\mathrm{FEV}_{1} / \mathrm{FVC}$ ratio decreased in both groups but a steeper decline was seen among non-exposed than among exposed.

Decline of the lung function variables $\mathrm{FEV}_{1}$ and $\mathrm{FVC}$ was assessed at the individual level and standardised for duration of the follow-up period (Fig. 3). Among nonexposed, the $\mathrm{FEV}_{1}$ had fallen almost $30 \mathrm{~mL} /$ year which was more than the fall of 10 $\mathrm{mL}$ /year among exposed. Overall small differences in FVC over this four-year period were seen.

\subsection{Associations between exposure to clean-up work and respiratory health outcomes at follow-up}

When taking into account only the follow up examinations, there were indications of a better respiratory health status among the exposed than among the non-exposed (Table 2). In particular, the $\mathrm{FEV}_{1} / \mathrm{FVC}$ ratio and the $\mathrm{FEF}_{25-75 \%}$ were significantly higher among exposed after adjustment for potential confounders. In addition, all cytokines and growth factors in EBC were less often detectable in exposed participants, the difference being statistically significant for interferon- $\gamma$. No differences were seen for 8-isoprostane levels and for the prevalence of BHR.

Finally, we excluded the non-exposed group from the analysis and evaluated the cross-sectional associations between degree of exposure to clean-up work and respiratory health outcomes at follow-up within the exposed only; thus, a comparison of highly vs. moderately exposed (Supplementary Table 4). There was a tendency that the $\mathrm{FEV}_{1} / \mathrm{FVC}$ ratio and the $\mathrm{FEF}_{25-75 \%}$ were lower among the highly exposed, although after adjustment the differences did not reach conventional levels of statistical significance (Table 3). In spite of the absence of a consistent pattern for the 
Zock, J.P., Rodríguez-Trigo, G., Rodríguez-Rodríguez, E., Souto-Alonso, A., Espinosa, A., PozoRodríguez, F., Gómez, F.P., Fuster, C., Castaño-Vinyals, G., Antó, J.M., Barberà, J.A. Evaluation of the persistence of functional and biological respiratory health effects in clean-up workers 67 years after the Prestige oil spill. Environment International: 2014, 62(1), 72-77

biomarkers, the highly exposed were significantly more likely to present detectable levels of IL-4 and TNF- $\alpha$ in EBC as compared to the moderately exposed clean-up workers.

\section{DISCUSSION}

In this longitudinal study we found that functional and biological respiratory health parameters in clean-up workers of the Prestige oil spill had not improved over a four-year follow-up period but there were no clear indications that the degree of exposure was associated with long-term effects. However, in a comparable control group of fishermen without exposure to clean-up work, who had less BHR and lower levels of respiratory biomarkers at baseline, these indices had importantly deteriorated precluding a firm conclusion on the persistence of respiratory health effects due the clean-up exposures of this major marine oil spill.

As a result of more pronounced changes in objectively measured respiratory health indices in non-exposed than in exposed, at follow-up (that is, 6 years after the spill) clean-up workers had a similar or for some parameters even better respiratory health than non-exposed. Given these remarkable changes among the non-exposed, this should not directly be interpreted as the absence of long-term health effect in cleanup workers. A potential explanation could be recovery from reversible respiratory effects. Indeed, the observed trends in spirometric indices among the exposed individuals may suggest a partial recovery from the (temporary) adverse effects of the exposure observed 2 years after the spill. However, it seems unlikely that such a recovery from earlier adverse effects would lead to a better lung function among the exposed than among the non-exposed at follow-up since there were no apparent differences in lung function between exposed and non-exposed at baseline. It is not impossible that a latent better (respiratory) health status of the exposed at baseline only became apparent four years later. One of the few respiratory health outcome variables in our study with an established reference in the general population is lung function measured by forced spirometry. We found an average $\mathrm{FEV}_{1}$ decline of $30 \mathrm{~mL}$ per year among the non-exposed, which is very close to the expected decline when considering reference equations of never-smoking men and women (Roca et al., 1998). A smaller $\mathrm{FEV}_{1}$ decline (about $10 \mathrm{~mL} /$ year) was observed among exposed, which could be indicative of a relative improvement of a short-lasting and reversible pulmonary defect. However, the follow-up period was only 4 years and this is generally considered rather short for a stable evaluation of lung function changes and for the detection of related longer-term effects of environmental exposures. For other health outcomes it is more difficult to compare our findings with a general population reference. Nevertheless, a group-level increase in BHR from 11\% to 33\% in 4 years among non-exposed is likely to be abnormal among lifetime non-smokers (Chinn et al., 2005).

In order to avoid systematically more or less exposed individuals during particular seasons, both in the baseline and in the follow-up surveys the strategy was to alternate the clinical testing between groups of exposed and groups of non-exposed. Exposed were studied between early December 2008 and mid-April 2009 while nonexposed were studied between late November 2008 and early April 2009. As a result, the average time of follow-up was also similar. We consider it unlikely that seasonal 
Zock, J.P., Rodríguez-Trigo, G., Rodríguez-Rodríguez, E., Souto-Alonso, A., Espinosa, A., PozoRodríguez, F., Gómez, F.P., Fuster, C., Castaño-Vinyals, G., Antó, J.M., Barberà, J.A. Evaluation of the persistence of functional and biological respiratory health effects in clean-up workexs 67 years after the Prestige oil spill. Environment International: 2014, 62(1), 72-77

variation in respiratory health due to climatic differences, influenza episodes and/or pollen season explained the observed changes in controls.

The easiest solution to overcome bias due to the unexpected changes in the control group is removing this non-exposed group from the analysis. Indeed we performed analyses limited to the more homogeneous exposed only, a group with presumably less selective participation both at baseline and at follow-up. This group could be divided into two subgroups according to the degree of exposure using four characteristics of clean-up work reported at baseline (Rodríguez-Trigo et al., 2010 and Zock et al., 2007), apparently large enough to perform meaningful analyses with reasonable statistical power. We had previously shown increasing trends of persistent respiratory symptoms among the highest exposed group using the same exposure classification as in the present analysis (Zock et al., 2012). Although in general there were no large and consistent differences in objective respiratory health parameters between highly and moderately exposed, there were some indications for differences in lung function and some cytokines at follow-up in the hypothesised direction. Non-exposed participants of the follow-up survey had more respiratory symptoms at the baseline evaluation than non-exposed individuals who were lost to follow-up. This selective participation was much less apparent among exposed and thus could have introduced a bias when comparing respiratory health status at follow-up between the exposed and non-exposed groups. Nevertheless, when limiting the baseline comparison of respiratory health indices to those who participated in the follow-up survey, the increased risk of BHR and elevated levels of respiratory biomarkers among exposed remained very similar. However, there were indications that lung function parameters indicative of airflow obstruction $\left(\mathrm{FEV}_{1} / \mathrm{FVC}\right)$ and of small airways disorders $\left(\mathrm{FEF}_{25-75 \%}\right)$ became on average higher among exposed when using this selected population. We interpret that the motivation of fishermen who had participated in clean-up activities was not largely influenced by their respiratory health status, while unexposed fishermen were more motivated to participate if they had been suffering respiratory problems. This phenomenon resulted in a small bias for some of the health outcomes of interest reducing the differences between cleanup workers and non-exposed controls.

In spite of the apparently limited bias due to selective participation, respiratory health status in the non-exposed group (lung function, BHR, respiratory biomarkers) deteriorated notably during the 4-year follow-up period. This was observed for both men and women and was not dependent on age group (results not presented). It is not easy to hypothesise a straightforward explanation of these observations. We initially tried to reduce selection bias at the time of the recruitment of non-exposed controls

for the baseline study in 2004-2005 by excluding fishermen who reported not having participated in clean-up operations because of health reasons (Rodríguez-Trigo et al., 2010). Indeed, there were no large differences in asthma prevalence between the exposed and non-exposed groups at baseline (Rodríguez-Trigo et al., 2010), and four years later the presence of respiratory and allergic conditions was still comparable in both groups of participants (Table 1). Perceived quality of life scores at baseline were higher among the exposed, particularly for the physical component of SF-12. However, these differences disappeared when controlling the comparisons for sex. In a previous follow-up study of the same base population 5 years after the Prestige oil spill, clean-up workers demonstrated an increased prevalence of respiratory symptoms as compared to non-exposed fishermen ( Zock et al., 2012). However, 
Zock, J.P., Rodríguez-Trigo, G., Rodríguez-Rodríguez, E., Souto-Alonso, A., Espinosa, A., PozoRodríguez, F., Gómez, F.P., Fuster, C., Castaño-Vinyals, G., Antó, J.M., Barberà, J.A. Evaluation of the persistence of functional and biological respiratory health effects in clean-up workexs 67 years after the Prestige oil spill. Environment International: 2014, 62(1), 72-77

among the never-smokers these differences were small and not statistically significant. This was in line with observations of the initial study 1-2 years after exposure where risk estimates for respiratory symptoms related to clean-up work were lowest among never-smokers ( Zock et al., 2007). On the other hand, functional and biological respiratory effects at baseline were predominantly found among never-smokers ( Rodríguez-Trigo et al., 2010). We anticipated that due to the concurrent and potentially (residual) confounding effect of cigarette smoking on lung function, BHR and respiratory oxidative stress, the possibility of detecting stronger associations with exposure to clean-up work was higher when limiting the analyses to lifetime non-smokers. We cannot exclude the possibility having missed potentially relevant long-term effects of clean-up exposures among smokers and/or ex-smokers. The main limitation of this study was that we identified and followed a relatively small non-exposed control group that (apart from the clean-up work) differed from the exposed clean-up workers in terms of sex and age distribution, although not in occupation. This control group appeared to be unstable, a health-related selection influenced the participation in the follow-up, and unforeseen changes in respiratory health indices hampered a proper comparison with the exposed clean-up workers. On the other hand, the main strength of this unique study is the longitudinal design using identical methodology at baseline and follow-up that allowed a proper evaluation of functional and biological respiratory health parameters over time.

In conclusion, although we found that objectively measured indices of respiratory health impairment in clean-up workers of the Prestige oil spill persisted up to six years after exposure, we could not formally demonstrate that this persistence was due to exposure. As suggested by the present results and others (Goldstein et al., 2011), longitudinal studies and repeated surveillance on long-term health effects in clean-up workers of oil spills are important. However, it is not clear which epidemiological designs are most appropriate, and several methodological issues should be taken into account. If the inclusion of a non-exposed control group is desired due to the chosen study design, a large, stable and comparable non-exposed population should be identified and followed over time. In addition, our study suggests that it may not be optimal to limit the follow-up to subgroups such as non-smokers. Otherwise, as shown in the present study, findings may become difficult to interpret and to be extrapolated to the entire collective of clean-up workers, let alone to other oil spills.

\section{ACKNOWLEDGMENTS}

This study was financially supported by the Instituto de Salud Carlos III/FEDER (grants FIS PI03/1685 and PI07/0086), the Spanish Respiratory Society (SEPAR), the Galician Health Service (SERGAS), the CIBER Enfermedades Respiratorias (CIBERES), and the CIBER Epidemiología y Salud Pública (CIBERESP). The authors wish to thank Marisa Rodríguez-Valcárcel and Luisa Vázquez-Rey (University Hospital A Coruña) for performing the clinical tests and Felip Burgos and Yolanda Torralba (Hospital Clínic, Barcelona) for advice on and quality control of the functional tests. 
Zock, J.P., Rodríguez-Trigo, G., Rodríguez-Rodríguez, E., Souto-Alonso, A., Espinosa, A., PozoRodríguez, F., Gómez, F.P., Fuster, C., Castaño-Vinyals, G., Antó, J.M., Barberà, J.A. Evaluation of the persistence of functional and biological respiratory health effects in clean-up workexs 67 years after the Prestige oil spill. Environment International: 2014, 62(1), 72-77

\section{APPENDIX A. SUPPLEMENTARY DATA}

\section{REFERENCES}

S. Chinn, D. Jarvis, C.M. Luczynska, U. Ackermann-Liebrich, J.M. Antó, I. Cerveri et al. An increase in bronchial responsiveness is associated with continuing or restarting smoking Am J Respir Crit Care Med, 172 (2005), pp. 956-961

B.D. Goldstein, H.J. Osofsky, M.Y. Lichtveld The Gulf oil spill N Engl J Med, 364 (2011), pp. 1334-1348

I. Horvath, J. Hunt, P.J. Barnes, K. Alving, A. Antczak, E. Baraldi et al. Exhaled breath condensate: methodological recommendations and unresolved questions Eur Respir J, 26 (2005), pp. 523-548

M.R. Miller, J. Hankinson, V. Brusasco, F. Burgos, R. Casaburi, A. Coates et al. Standardisation of spirometry Eur Respir J, 26 (2005), pp. 319-338

J. Roca, F. Burgos, J. Sunyer, M. Saez, S. Chinn, J.M. Antó et al. References values for forced spirometry Eur Respir J, 11 (1998), pp. 1354-1362

G. Rodríguez-Trigo, J.P. Zock, F. Pozo-Rodríguez, F.P. Gómez, G. Monyarch, L. Bouso et al. Health changes in fishermen 2 years after clean-up of the Prestige oil spill Ann Intern Med, 153 (2010), pp. 489-498

G. Vilagut, J.M. Valderas, M. Ferrer, O. Garin, E. López-García, J. Alonso Interpretation of SF-36 and SF-12 questionnaires in Spain: physical and mental components Med Clin (Barc), 130 (2008), pp. 726-735

J.P. Zock, G. Rodríguez-Trigo, F. Pozo-Rodríguez, J.A. Barberà, L. Bouso, Y. Torralba et al. Prolonged respiratory symptoms in fishermen who participated in clean-up activities of the Prestige oil spill Am J Respir Crit Care Med, 176 (2007), pp. 610-616

J.P. Zock, G. Rodríguez-Trigo, E. Rodríguez-Rodríguez, A. Espinosa, F. Pozo-Rodríguez, F.P. Gómez et al. Persistent respiratory symptoms in clean-up workers 5 years after the Prestige oil spill Occup Environ Med, 69 (2012), pp. 508-513 
Zock, J.P., Rodríguez-Trigo, G., Rodríguez-Rodríguez, E., Souto-Alonso, A., Espinosa, A., PozoRodríguez, F., Gómez, F.P., Fuster, C., Castaño-Vinyals, G., Antó, J.M., Barberà, J.A. Evaluation of the persistence of functional and biological respiratory health effects in clean-up workexs 67 years after the Prestige oil spill. Environment International: 2014, 62(1), 72-77

\section{TABLES}

Fig. 1. Flow chart showing the design of the different stages of the study.

Prestige coastal oil spill and subsequent clean-up work

(November 2002 onwards)
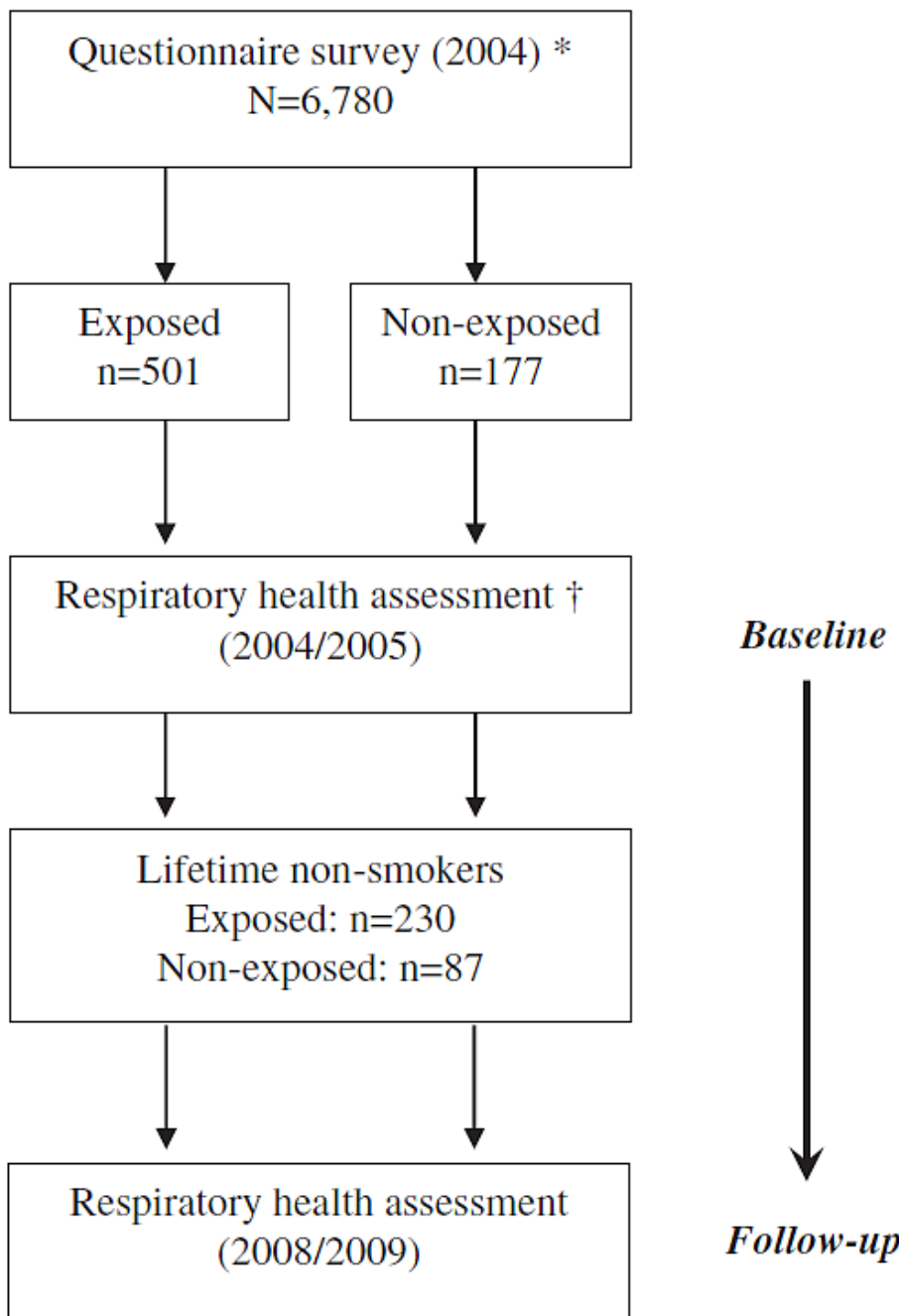

Follow-up

* Detailed description in Zock et al. (2007).

† Detailed description in Rodríguez-Trigo et al. (2010). 
Zock, J.P., Rodríguez-Trigo, G., Rodríguez-Rodríguez, E., Souto-Alonso, A., Espinosa, A., PozoRodríguez, F., Gómez, F.P., Fuster, C., Castaño-Vinyals, G., Antó, J.M., Barberà, J.A. Evaluation of the persistence of functional and biological respiratory health effects in clean-up workexs 67 years after the Prestige oil spill. Environment International: 2014, 62(1), 72-77

\section{Table 1}

Demographic and respiratory health characteristics of the study population at baseline (2004/2005) and at follow-up (2008/2009). Fishermen involved in Prestige oil spill, Galicia, Spain.

\begin{tabular}{|c|c|c|c|c|}
\hline & \multicolumn{2}{|c|}{ Exposed $(n=158)$} & \multicolumn{2}{|c|}{ Non-exposed $(n=57)$} \\
\hline & Baseline & Follow-up & Baseline & Follow-up \\
\hline Women & \multicolumn{2}{|l|}{$82(52 \%)$} & \multicolumn{2}{|l|}{$43(75 \%)$} \\
\hline $\begin{array}{l}\text { Active fishermen or } \\
\text { shellfish gatherers }\end{array}$ & $158(100 \%)$ & $124(78 \%)$ & $57(100 \%)$ & $45(79 \%)$ \\
\hline Age (years): mean (SD) & $46.8(11.3)$ & $51.0(11.3)$ & $51.8(8.2)$ & $55.8(8.2)$ \\
\hline $\begin{array}{l}\text { Time of follow-up (years): } \\
\text { mean (range) }\end{array}$ & \multicolumn{2}{|c|}{4.2 (3.8 to 4.7 ) } & \multicolumn{2}{|c|}{$4.1(3.8$ to 4.3$)$} \\
\hline $\begin{array}{l}\text { Body mass index }\left(\mathrm{kg} \mathrm{m}^{-2}\right) \text { : } \\
\text { mean (SD) }\end{array}$ & $28.9(3.7)$ & $29.0(3.7)$ & $30.2(4.6)$ & $30.3(4.9)$ \\
\hline Ever asthma & $9(6 \%)$ & $12(8 \%)$ & $4(7 \%)$ & $6(11 \%)$ \\
\hline Nasal allergy or rhinitis & $13(8 \%)$ & $22(14 \%)$ & $11(19 \%)$ & $7(12 \%)$ \\
\hline Reported allergies & $21(13 \%)$ & $33(21 \%)$ & $8(14 \%)$ & $13(23 \%)$ \\
\hline Atopy ${ }^{a}$ & $22(14 \%)$ & n.a. & $8(14 \%)$ & n.a. \\
\hline Total IgE: GM (GSD) & $20.3(1.4)$ & n.a. & $22.0(1.5)$ & n.a. \\
\hline $\begin{array}{l}\text { Physical component quality } \\
\text { of life }{ }^{\text {b: }} \text { median }\end{array}$ & 51.1 & n.a. & 46.2 & n.a. \\
\hline $\begin{array}{l}\text { Mental component quality } \\
\text { of life }{ }^{\text {b: }} \text { median }\end{array}$ & 53.1 & n.a. & 50.8 & n.a. \\
\hline
\end{tabular}

Numbers of participants (\%) are given, unless otherwise indicated.

${ }^{\text {a }}$ Skin prick testing to common inhalant allergens ${ }^{\mathrm{b}} \mathrm{SF}-12 ; n=141+56$. A higher score indicates a better quality of life. n.a. data not available. 
Zock, J.P., Rodríguez-Trigo, G., Rodríguez-Rodríguez, E., Souto-Alonso, A., Espinosa, A., PozoRodríguez, F., Gómez, F.P., Fuster, C., Castaño-Vinyals, G., Antó, J.M., Barberà, J.A. Evaluation of the persistence of functional and biological respiratory health effects in clean-up workexs 67 years after the Prestige oil spill. Environment International: 2014, 62(1), 72-77

Fig. 2. Group-level changes in selected functional and biological respiratory health outcomes between the baseline and follow-up studies. Individualswith complete data for the respective health outcome variable both at baseline (indicated by shaded bars) and at follow-up (indicated by black bars) were included.
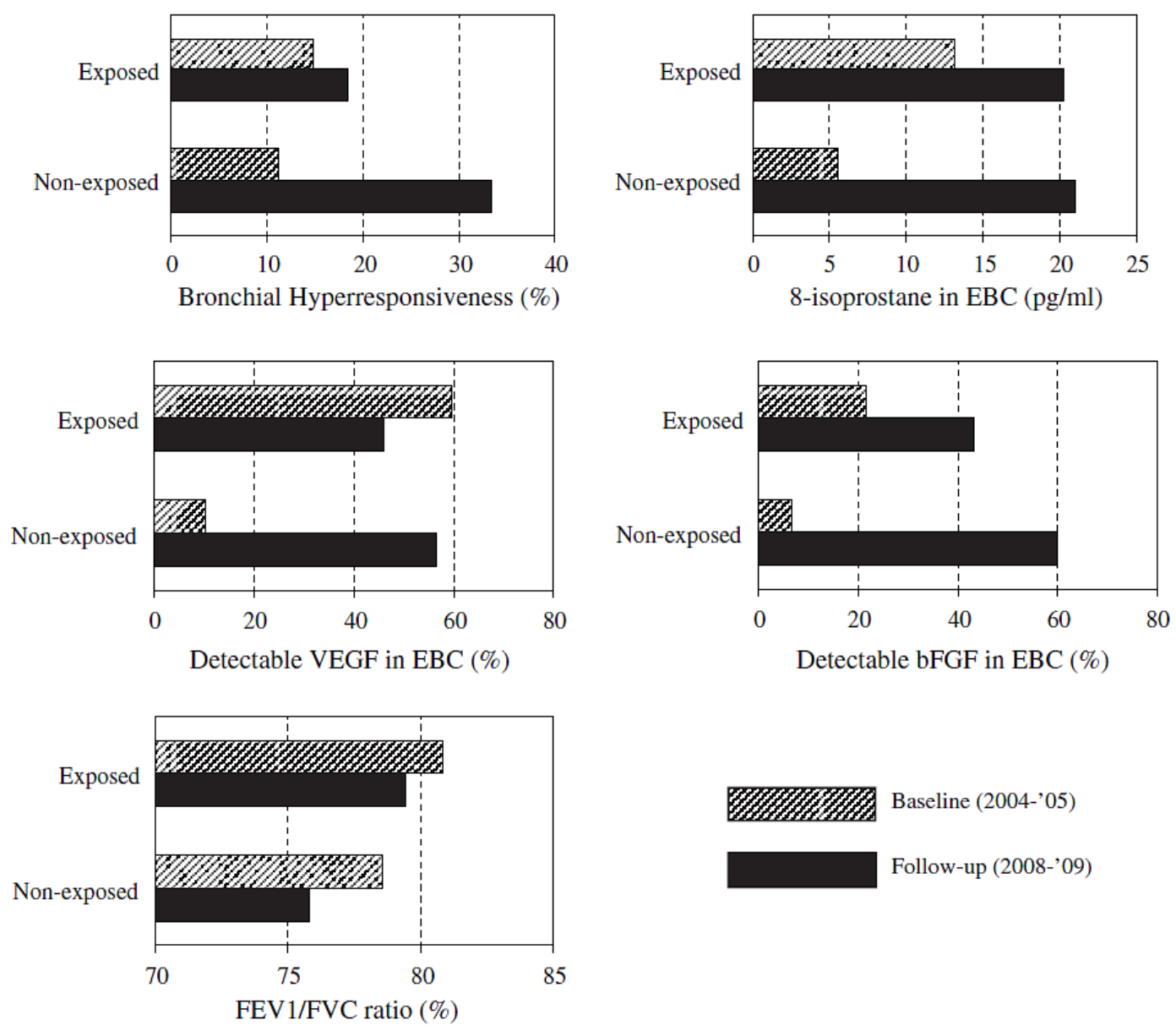

Baseline (2004-’05)

Follow-up (2008-'09) 
Zock, J.P., Rodríguez-Trigo, G., Rodríguez-Rodríguez, E., Souto-Alonso, A., Espinosa, A., PozoRodríguez, F., Gómez, F.P., Fuster, C., Castaño-Vinyals, G., Antó, J.M., Barberà, J.A. Evaluation of the persistence of functional and biological respiratory health effects in clean-up workexs 67 years after the Prestige oil spill. Environment International: 2014, 62(1), 72-77

Fig. 3. Mean annual lung function decline between the baseline and follow-up studies in exposed and non-exposed participants.

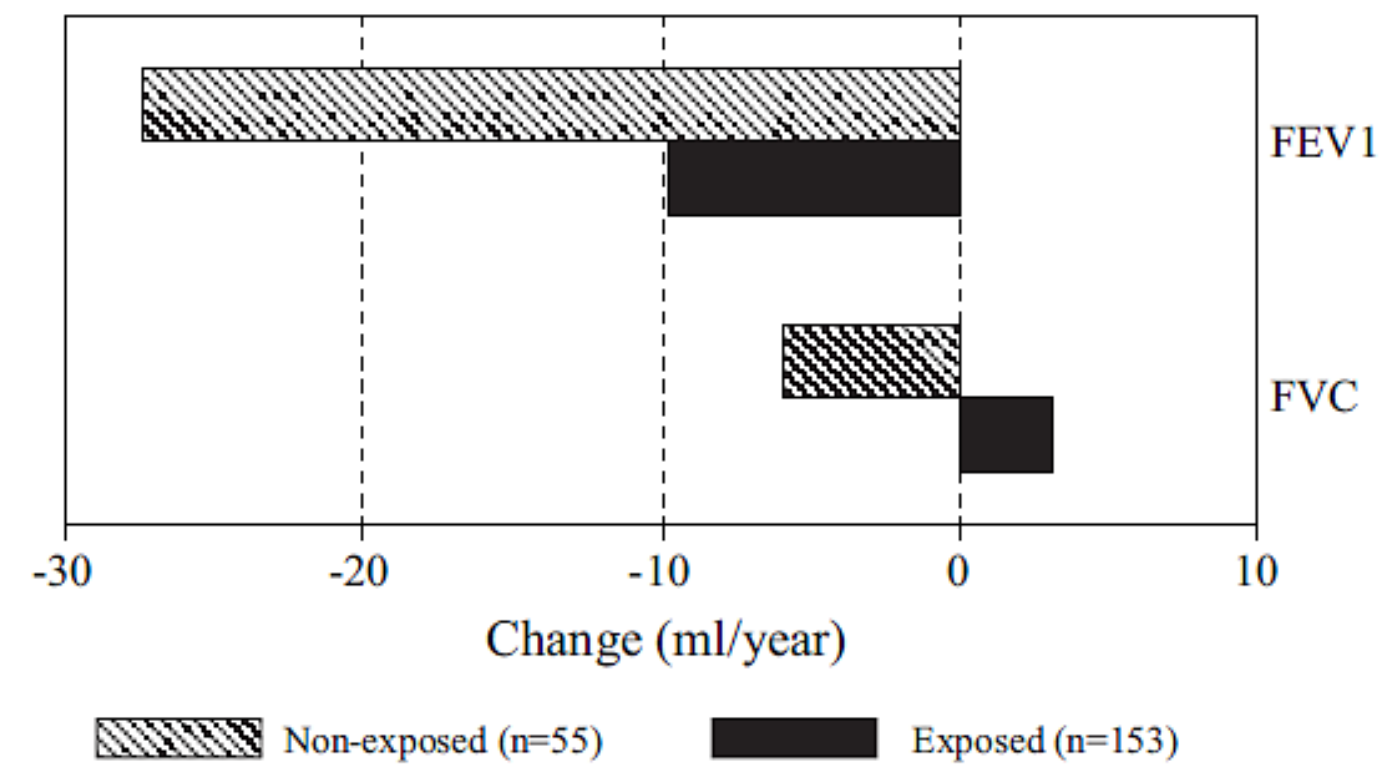


Zock, J.P., Rodríguez-Trigo, G., Rodríguez-Rodríguez, E., Souto-Alonso, A., Espinosa, A., PozoRodríguez, F., Gómez, F.P., Fuster, C., Castaño-Vinyals, G., Antó, J.M., Barberà, J.A. Evaluation of the persistence of functional and biological respiratory health effects in clean-up workers 67 years after the Prestige oil spill. Environment International: 2014, 62(1), 72-77

\section{Table 2}

Cross-sectional associations between exposure to clean-up work and functional and biological respiratory health outcomes at follow-up. Fishermen involved in Prestige oil spill, Galicia, Spain, 2008/2009.

\begin{tabular}{|c|c|c|c|}
\hline Respiratory health outcome variable & $\begin{array}{l}\text { Exposed } \\
(n=158)\end{array}$ & $\begin{array}{l}\text { Non-exposed } \\
(n=57)\end{array}$ & \\
\hline Lung function & Mean & Mean & $\begin{array}{l}\text { Difference }^{\text {a }} \\
(95 \% C I)\end{array}$ \\
\hline $\mathrm{FEV}_{1}(\mathrm{~mL})$ & 3108 & 2722 & $30(-95$ to 155$)$ \\
\hline $\mathrm{FVC}(\mathrm{mL})$ & 3906 & 3596 & $-98(-251$ to 54$)$ \\
\hline $\mathrm{FEV}_{1} / \mathrm{FVC}$ ratio (\%) & 79.3 & 75.7 & 2.8 (0.9 to 4.7$)$ \\
\hline $\mathrm{FEF}_{25-75 \%}(\mathrm{~mL} / \mathrm{s})$ & 2839 & 2117 & $\begin{array}{l}296(36 \text { to } 555) \\
\text { OR }(95 \% C I)^{\mathrm{b}}\end{array}$ \\
\hline Bronchial hyperresponsiveness ${ }^{c}$ & $27(19 \%)$ & $18(35 \%)$ & $0.6(0.3$ to 1.2$)$ \\
\hline Biomarkers in $E B C$ & $G M$ & $G M$ & $\begin{array}{l}\text { GM Ratio }^{\mathrm{b}} \\
(95 \% \text { CI) }\end{array}$ \\
\hline 8-isoprostane ( $\mathrm{GM}$ in $\mathrm{pg} / \mathrm{mL}$ ) & 18.5 & 20.8 & $1.0(0.7$ to 1.4$)$ \\
\hline Biomarkers in EBC & Detectable & Detectable & OR $(95 \% C I)^{\mathrm{b}}$ \\
\hline $\begin{array}{l}\text { Vascular Endothelial } \\
\text { Growth Factor }\end{array}$ & $63(40 \%)$ & $26(51 \%)$ & $0.6(0.3$ to 1.1$)$ \\
\hline $\begin{array}{l}\text { Basic Fibroblastic } \\
\text { Growth Factor }\end{array}$ & $80(51 \%)$ & $29(57 \%)$ & $0.7(0.4$ to 1.4$)$ \\
\hline Interleukin-1 $\beta$ & $38(24 \%)$ & $18(35 \%)$ & $0.6(0.3$ to 1.2$)$ \\
\hline Interleukin-2 & 0 & 0 & - \\
\hline Interleukin-4 & $25(16 \%)$ & $11(22 \%)$ & $0.5(0.2$ to 1.3$)$ \\
\hline Interleukin-6 & $10(6 \%)$ & $5(10 \%)$ & $0.7(0.2$ to 2.3$)$ \\
\hline Interleukin-8 & $23(15 \%)$ & $10(20 \%)$ & $0.8(0.4$ to 1.9$)$ \\
\hline Tumour Necrosis Factor- $\alpha$ & $65(41 \%)$ & $28(55 \%)$ & $0.6(0.3$ to 1.1$)$ \\
\hline Interferon- $\gamma$ & $19(12 \%)$ & $12(24 \%)$ & $0.5(0.2$ to 1.0$)$ \\
\hline Monocyte Chemotactic Protein-1 & $82(52 \%)$ & $33(65 \%)$ & $0.6(0.3$ to 1.2$)$ \\
\hline
\end{tabular}

Numbers of participants (\%) are given, unless otherwise indicated.

a Adjusted for sex, age and height.

b Adjusted for sex and age.

c Methacholine dose of $2 \mathrm{mg}$ or less causing a $20 \%$ fall in $\mathrm{FEV}_{1}(n=147+52)$. 
Zock, J.P., Rodríguez-Trigo, G., Rodríguez-Rodríguez, E., Souto-Alonso, A., Espinosa, A., PozoRodríguez, F., Gómez, F.P., Fuster, C., Castaño-Vinyals, G., Antó, J.M., Barberà, J.A. Evaluation of the persistence of functional and biological respiratory health effects in clean-up workefs 67 years after the Prestige oil spill. Environment International: 2014, 62(1), 72-77

Table 3

Associations between the degree of exposure to clean-up work and functional and biological respiratory health outcomes at follow-up. Fishermen involved in Prestige oil spill, Galicia, Spain, 2008/2009.

\begin{tabular}{|c|c|c|c|}
\hline $\begin{array}{l}\text { Respiratory health } \\
\text { outcome variable }\end{array}$ & $\begin{array}{l}\text { Moderately } \\
\text { exposed } \\
(n=83)\end{array}$ & $\begin{array}{l}\text { Highly } \\
\text { exposed } \\
(n=75)\end{array}$ & \\
\hline Lung function & Mean & Mean & $\begin{array}{l}\text { Difference a } \\
(95 \% C I)\end{array}$ \\
\hline $\mathrm{FEV}_{1}(\mathrm{~mL})$ & 2894 & 3343 & $-32(-153$ to 90$)$ \\
\hline $\mathrm{FVC}(\mathrm{mL})$ & 3649 & 4188 & $7(-143$ to 158$)$ \\
\hline $\mathrm{FEV}_{1} / \mathrm{FVC}$ ratio (\%) & 79.1 & 79.6 & $-1.0(-2.9$ to 0.8$)$ \\
\hline $\mathrm{FEF}_{25-75 \%}(\mathrm{~mL} / \mathrm{s})$ & 2605 & 3096 & $\begin{array}{l}-118(-390 \text { to } 153) \\
\text { OR }(95 \% C I)^{\mathrm{b}}\end{array}$ \\
\hline $\begin{array}{l}\text { Bronchial } \\
\text { hyperresponsiveness }{ }^{c}\end{array}$ & $15(21 \%)$ & $12(17 \%)$ & $1.2(0.5$ to 2.9$)$ \\
\hline Biomarkers in $E B C$ & $G M$ & $G M$ & $\begin{array}{l}\text { GM Ratio } \\
(95 \% C I)^{\text {b }}\end{array}$ \\
\hline $\begin{array}{l}\text { 8-isoprostane } \\
\text { (GM in pg/mL) }\end{array}$ & 18.9 & 18.0 & $1.0(0.7$ to 1.4$)$ \\
\hline Biomarkers in $E B C$ & Detectable & Detectable & OR $(95 \% C I)^{\mathrm{b}}$ \\
\hline $\begin{array}{l}\text { Vascular Endothelial } \\
\text { Growth Factor }\end{array}$ & $32(39 \%)$ & $31(41 \%)$ & $1.0(0.5$ to 1.9$)$ \\
\hline $\begin{array}{l}\text { Basic Fibroblastic } \\
\text { Growth Factor }\end{array}$ & $36(43 \%)$ & $44(59 \%)$ & $1.8(0.9$ to 3.5$)$ \\
\hline Interleukin-1 $\beta$ & $16(19 \%)$ & $22(29 \%)$ & $1.8(0.8$ to 3.8$)$ \\
\hline Interleukin-2 & 0 & 0 & - \\
\hline Interleukin-4 & $7(8 \%)$ & $18(24 \%)$ & $2.7(1.0$ to 7.3$)$ \\
\hline Interleukin-6 & $5(6 \%)$ & $5(7 \%)$ & $1.4(0.4$ to 5.3$)$ \\
\hline Interleukin-8 & $10(12 \%)$ & $13(17 \%)$ & $2.0(0.8$ to 5.0$)$ \\
\hline $\begin{array}{l}\text { Tumour Necrosis } \\
\text { Factor- } \alpha\end{array}$ & $27(33 \%)$ & $38(51 \%)$ & $2.2(1.1$ to 4.4$)$ \\
\hline Interferon- $\gamma$ & $12(14 \%)$ & $7(9 \%)$ & $0.6(0.2$ to 1.6$)$ \\
\hline $\begin{array}{l}\text { Monocyte Chemotactic } \\
\text { Protein-1 }\end{array}$ & $44(53 \%)$ & $38(51 \%)$ & $0.8(0.4$ to 1.6$)$ \\
\hline
\end{tabular}

Numbers of participants (\%) are given, unless otherwise indicated.

a Adjusted for sex, age and height.

b Adjusted for sex and age.

${ }^{c}$ Methacholine dose of $2 \mathrm{mg}$ or less causing a $20 \%$ fall in $\mathrm{FEV}_{1}(n=74+73)$. 


\section{Electronic Supplementary Material}

Evaluation of the persistence of functional and biological respiratory health effects in clean-up workers 6 years after the Prestige oil spill

Jan-Paul Zock, Gema Rodríguez-Trigo, Emma Rodríguez-Rodríguez, Aina Espinosa, Francisco Pozo-Rodríguez, Federico P.Gómez, Carme Fuster, Gemma Castaño-Vinyals, Josep M. Antó, and Joan A. Barberà

Supplementary Table 1: Reasons for loss to follow-up

\begin{tabular}{lcc}
\hline & $\begin{array}{c}\text { Exposed } \\
(\mathrm{n}=72)\end{array}$ & $\begin{array}{c}\text { Non-Exposed } \\
(\mathrm{n}=30)\end{array}$ \\
\hline Error contact information & $14(19 \%)$ & $1(3 \%)$ \\
Unable to be contacted & $8(11 \%)$ & $6(20 \%)$ \\
Not willing to participate & $18(25 \%)$ & $17(57 \%)$ \\
Agreed but did not show up & $31(43 \%)$ & $6(20 \%)$ \\
Deceased & $1(1 \%)$ & $0(0 \%)$ \\
\hline
\end{tabular}




\section{Supplementary Table 2: Baseline demographic and respiratory health characteristics of participants and non-participants of the follow-up study}

\begin{tabular}{|c|c|c|c|c|c|c|}
\hline \multirow[b]{3}{*}{ Baseline characteristic } & \multirow{2}{*}{\multicolumn{2}{|c|}{$\begin{array}{l}\text { Eligible exposed } \\
\text { Participation follow-up }\end{array}$}} & \multicolumn{4}{|c|}{ Eligible non-exposed } \\
\hline & & & & Participati & follow-up & \multirow[b]{2}{*}{$\mathrm{p}$} \\
\hline & $\begin{array}{c}\text { Yes } \\
(n=158)\end{array}$ & $\begin{array}{c}\text { No } \\
(n=72)\end{array}$ & $\mathrm{p}$ & $\begin{array}{c}\text { Yes } \\
(n=57)\end{array}$ & $\begin{array}{c}\text { No } \\
(n=30)\end{array}$ & \\
\hline Age in years: mean (SD) & $47(11)$ & $46(12)$ & 0.57 & $52(8)$ & $51(11)$ & 0.64 \\
\hline Women & $82(52 \%)$ & $27(38 \%)$ & 0.04 & $43(75 \%)$ & $21(70 \%)$ & 0.59 \\
\hline Body mass index $\left(\mathrm{kg} \cdot \mathrm{m}^{-2}\right)$ : mean (SD) & $28.9(3.7)$ & $29.5(4.2)$ & 0.32 & $30.2(4.6)$ & $31.7(5.5)$ & 0.17 \\
\hline Lower Respiratory Tract Symptoms * & $54(35 \%)$ & $18(26 \%)$ & 0.22 & $20(38 \%)$ & $3(11 \%)$ & 0.01 \\
\hline Nasal Symptoms $\dagger$ & $56(36 \%)$ & $17(24 \%)$ & 0.07 & $17(30 \%)$ & $7(23 \%)$ & 0.52 \\
\hline Inhaled Medication & $19(12 \%)$ & $7(10 \%)$ & 0.62 & $3(5 \%)$ & $4(13 \%)$ & 0.19 \\
\hline Oral Medication & $24(15 \%)$ & $8(11 \%)$ & 0.43 & $7(12 \%)$ & $3(10 \%)$ & 0.75 \\
\hline Ever asthma & $9(6 \%)$ & $6(8 \%)$ & 0.45 & $4(7 \%)$ & $2(7 \%)$ & 0.95 \\
\hline Nasal allergy or rhinitis & $13(8 \%)$ & $4(6 \%)$ & 0.47 & $11(19 \%)$ & $1(3 \%)$ & 0.04 \\
\hline Atopy $\ddagger$ & $22(14 \%)$ & $16(22 \%)$ & 0.12 & $8(14 \%)$ & $4(13 \%)$ & 0.93 \\
\hline Bronchial hyperresponsiveness $\S$ & $22(16 \%)$ & $8(13 \%)$ & 0.59 & $5(10 \%)$ & $2(7 \%)$ & 0.65 \\
\hline Anxiety & 64 (41\%) & $16(22 \%)$ & 0.01 & $14(27 \%)$ & $13(43 \%)$ & 0.13 \\
\hline Health belief effect & $31(20 \%)$ & $6(8 \%)$ & 0.03 & $1(2 \%)$ & $0(0 \%)$ & 0.45 \\
\hline Physical component quality of life $\|$ & 51.1 & 52.9 & 0.30 & 46.2 & 47.5 & 0.68 \\
\hline Mental component quality of life\| & 53.1 & 54.1 & 0.43 & 50.8 & 52.3 & 0.92 \\
\hline
\end{tabular}

Numbers of participants (\%) are given, unless otherwise indicated.

* Wheeze with breathlessness; wheeze apart from colds; nocturnal attacks of shortness of breath; chronic cough and/or chronic phlegm

$\dagger$ A problem with sneezing, or a runny or a blocked nose when not having a cold or the flu in the last 12 months

¥ Skin prick testing to common inhalant allergens $(\mathrm{n}=229+87)$

$\S$ Methacholine dose of $2 \mathrm{mg}$ or less causing a 20\% fall in FEV1 ( $\mathrm{n}=198+77)$

|| SF-12; median scores. A higher SF-12 score indicates a better quality of life.

P values were derived from Student's $t$ tests (age), Chi-square tests (categorical variables) or WilcoxonMann-Whitney $U$ test (quality of life components) 
Supplementary Table 3: Associations between participation in clean-up work and selected functional and biological respiratory health outcomes at baseline, according to participation in the follow-up study

\begin{tabular}{|c|c|c|c|c|c|c|}
\hline \multirow[b]{2}{*}{ Respiratory health outcome variable } & \multicolumn{3}{|c|}{ All participants of the baseline study } & \multicolumn{3}{|c|}{ Participants of the follow-up study } \\
\hline & $\begin{array}{l}\text { Exposed } \\
(n=230)\end{array}$ & $\begin{array}{c}\text { Non-Exposed } \\
(\mathrm{n}=87)\end{array}$ & & $\begin{array}{l}\text { Exposed } \\
(n=158)\end{array}$ & $\begin{array}{l}\text { Non-Exposed } \\
\quad(n=57)\end{array}$ & \\
\hline Lung function & Mean & Mean & $\begin{array}{c}\text { Difference * } \\
(95 \% \text { CI) }\end{array}$ & Mean & Mean & $\begin{array}{l}\text { Difference } \\
(95 \% \text { CI }) *\end{array}$ \\
\hline $\mathrm{FEV}_{1}(\mathrm{~mL})$ & 3221 & 2872 & $-44(-165$ to 78$)$ & 3178 & 2827 & $-9(-139$ to 122$)$ \\
\hline FVC (mL) & 3966 & 3596 & $-66(-216$ to 83$)$ & 3919 & 3611 & $-87(-247$ to 73$)$ \\
\hline $\mathrm{FEV}_{1} / \mathrm{FVC}$ ratio (\%) & 81.0 & 80.0 & $0.0(-1.4$ to 1.4$)$ & 80.9 & 78.5 & $1.3(-0.4$ to 3.0$)$ \\
\hline \multirow{2}{*}{$\mathrm{FEF}_{25-75 \%}(\mathrm{~mL} / \mathrm{s})$} & 3141 & 2662 & -17 (-267 to 232$)$ & 3082 & 2460 & 163 (-126 to 452$)$ \\
\hline & & & OR $(95 \% C I) \dagger$ & & & OR $(95 \% C I) \dagger$ \\
\hline Bronchial hyperresponsiveness $\ddagger$ & $30 / 198(15 \%)$ & $7 / 77(9 \%)$ & $2.7(1.1$ to 6.6$)$ & $22 / 137(16 \%)$ & $5 / 49(10 \%)$ & $2.2(0.8$ to 6.5$)$ \\
\hline Biomarkers in EBC & $G M$ & $G M$ & $\begin{array}{c}\text { GM Ratio } \dagger \\
(95 \% \text { CI) }\end{array}$ & $G M$ & $G M$ & $\begin{array}{l}\text { GM Ratio } \\
(95 \% \text { CI }) \dagger\end{array}$ \\
\hline 8-isoprostane (GM in pg/mL) & $14.0(\mathrm{n}=77)$ & $5.6(n=79)$ & 2.5 (1.6 to 3.6$)$ & $13.1(n=59)$ & $5.6(n=52)$ & $2.3(1.4$ to 3.6$)$ \\
\hline Biomarkers in EBC & Detectable & Detectable & OR $(95 \% C I) \dagger$ & Detectable & Detectable & OR $(95 \% C I) \dagger$ \\
\hline Vascular Endothelial Growth Factor & $29 / 49(59 \%)$ & $7 / 50(14 \%)$ & 8.8 (3.3 to 24$)$ & 22/37 (59\%) & 3/36 (8\%) & 15.5 (4.0 to 61$)$ \\
\hline Basic Fibroblastic Growth Factor & $11 / 49(22 \%)$ & $3 / 50(6 \%)$ & 4.5 (1.1 to 18$)$ & 8/37 (22\%) & 2/36 (6\%) & $3.8(0.7$ to 20$)$ \\
\hline
\end{tabular}

Numbers of participants (\%) are given, unless otherwise indicated.

* Adjusted for sex, age and height $\quad \dagger$ Adjusted for sex and age

$\ddagger$ Methacholine dose of 2 mg or less causing a 20\% fall in $\mathrm{FEV}_{1}$ 
Supplementary Table 4: Characterisation of the degree of exposure

\begin{tabular}{lcccc}
\hline & \multicolumn{2}{c}{$\begin{array}{c}\text { Moderately exposed } \\
(\mathrm{n}=83)\end{array}$} & \multicolumn{2}{c}{$\begin{array}{c}\text { Highly exposed } \\
(\mathrm{n}=75)\end{array}$} \\
Characteristic of clean-up work & Mean & Range & Mean & Range \\
\hline Total number of days & 100 & 15 to 349 & 163 & 44 to 356 \\
Average number of hours per day & 6.0 & 4 to 11 & 6.9 & 5 to 14 \\
Number of activities & 4.5 & 2 to 10 & 6.3 & 5 to 9 \\
Never or rare use of face mask & $59 \%$ & -- & $100 \%$ & -- \\
\hline Demographic characteristics & & & & - \\
Female sex & $61 \%$ & -- & $41 \%$ & - \\
Age (years): mean (SD) & 54.2 & $(10.0)$ & 47.5 & $(11.6)$ \\
\hline
\end{tabular}

